\title{
Differences in the glucose-induced insulin response and the peripheral insulin responsiveness between neonatal calves of the Belgian Blue, Holstein-Friesian, and East Flemish breeds
}

\author{
P. Bossaert, ${ }^{* 1}$ J. L. M. R. Leroy, $†$ S. De Campeneere,‡ S. De Vliegher, ${ }^{*}$ and G. Opsomer* \\ *Department of Reproduction, Obstetrics and Herd Health, Faculty of Veterinary Medicine, Ghent University, Salisburylaan 133,9820 Merelbeke, \\ Belgium \\ †Laboratory for Veterinary Physiology, Department of Veterinary Sciences, Faculty of Biomedical, Pharmaceutical and Veterinary Sciences, \\ University of Antwerp, Universiteitsplein 1, 2610 Wilrijk, Belgium \\ ‡Department of Animal Sciences, Institute for Agricultural and Fisheries Research, Scheldeweg 68, 9090 Melle, Belgium
}

\begin{abstract}
Decreased insulin sensitivity (IS) in dairy cows supports milk yield but increases the risk for metabolic and reproductive disorders. Although several inducers of decreased IS are known, it is unclear to what extent it is congenitally determined. The main aim was to investigate differences in IS between neonatal calves of the Belgian Blue (BB) breed, reared for beef production, and the Holstein-Friesian (HF) breed, reared for milk yield. Additionally, a small number of East Flemish (EF) calves, a local dual-purpose breed, were compared with the 2 other breeds. Ten BB, $12 \mathrm{HF}$, and $4 \mathrm{EF}$ calves with similar age, ration, and housing were selected. In the intravenous glucose tolerance test, blood samples were taken at regular intervals after an intravenous glucose bolus of $150 \mathrm{mg} / \mathrm{kg}$. Area under the curve (AUC), peak concentration, and elimination rate of insulin and glucose were computed. The quantitative insulin sensitivity check index (QUICKI) and revised QUICKI were computed using basal glucose, insulin, and nonesterified fatty acid concentrations. In the intravenous insulin tolerance test, blood samples were obtained from 4 calves of each breed at regular times after an intravenous insulin challenge of $0.05 \mathrm{IU} / \mathrm{kg}$. Based on the decline in glucose concentrations relative to basal levels, the insulin-stimulated blood glucose response was computed. Basal insulin concentrations were higher in $\mathrm{HF}(1.58 \pm 0.40 \mu \mathrm{U} / \mathrm{mL})$ than in $\mathrm{BB}$ calves $(0.35 \pm 0.09 \mathrm{mmol} / \mathrm{L})$. Compared with $\mathrm{BB}$ calves, $\mathrm{HF}$ and $\mathrm{EF}$ calves had higher basal glucose concentrations $(4.40 \pm 0.16$ vs. $5.70 \pm 0.35$ and $5.81 \pm 0.13 \mathrm{mmol} / \mathrm{L}$, respectively), insulin peak concentrations $(4.62 \pm 1.09$ vs. $9.70 \pm 1.45$ and $16.44 \pm 5.58 \mu \mathrm{U} / \mathrm{mL}$, respectively), insulin AUC $(86.71 \pm 18.81$ vs. $222.65 \pm 45.00$ and $293.69 \pm 109.22 \mu \mathrm{U} / \mathrm{mL} \cdot \mathrm{min}$, respectively), and glucose
\end{abstract}

Received March 16, 2009

Accepted June 8, 2009.

${ }^{1}$ Corresponding author: Philippe.Bossaert@ugent.be
AUC $(256.22 \pm 17.53$ vs. $335.66 \pm 18.74$ and $321.03 \pm$ $10.05 \mathrm{mmol} / \mathrm{L} \cdot \mathrm{min}$, respectively). Glucose elimination rates were lower in $\mathrm{HF}(1.37 \pm 0.22 \% / \mathrm{min})$ than in $\mathrm{BB}$ calves $(2.35 \pm 0.25 \% / \mathrm{min})$. The QUICKI was lower in $\mathrm{HF}$ and $\mathrm{EF}$ than in $\mathrm{BB}$ calves $(0.52 \pm 0.039$ and $0.57 \pm 0.068$ vs. $0.76 \pm 0.038$, respectively), and the revised QUICKI was lower in HF $(0.86 \pm 0.11)$ than in $\mathrm{BB}$ calves $(1.59 \pm 0.17)$. The insulin-stimulated blood glucose response did not differ between breeds. Because management differences were negligible, our results suggest breed-specific differences in glucose partitioning and IS. These findings may reflect different rearing purposes of the breeds, although extrapolation of the data to adult animals should be done cautiously.

Key words: dairy cow, insulin sensitivity, neonatal calf, congenital

\section{INTRODUCTION}

The specific metabolism of high-yielding dairy cows during early lactation is associated with a high risk of reproductive and metabolic disorders, causing considerable economic damage (Lucy, 2001). During transition from gestation to lactation, changes in the metabolic hormone concentrations and the tissue responsiveness to such hormones take place to assign energetic priority to the uterus and mammary gland (Bauman and Currie, 1980; Bell and Bauman, 1997). The postpartum decline in basal insulin concentrations and glucose-induced insulin secretion (Bossaert et al., 2008) plays a key role in directing the energy flow. Low insulin concentrations reduce the glucose uptake by insulin-dependent organs, such as adipose and muscle tissue; increase the glucose availability for the insulin-independent mammary gland (van Knegsel et al., 2007); and favor lipolysis, proteolysis, and gluconeogenesis (Cunningham and Klein, 2007). Additionally, cows develop a mild insulin resistance (IR) during pregnancy and lactation, which further supports the glucose-sparing state induced by low insulin levels (Bell, 1995; Pires et al., 2007). 
These mechanisms that favor milk yield are unfavorable for fertility. Low insulin levels are deleterious for granulosa cell proliferation and function, whereas elevated NEFA concentrations are potentially toxic for oocytes and granulosa cells, as reviewed by Leroy et al. (2008). Additionally, a decrease in insulin concentration and insulin sensitivity (IS) and elevated NEFA levels increase the risk for metabolic disorders such as hepatolipidosis, abomasal displacement, and ketoacidosis (Veenhuizen et al., 1991; Oikawa and Oetzel, 2006).

The potential of the cow for energy partitioning is heritable. Cows with a high genetic merit for milk yield shift additional ingested energy toward milk production rather than improving their energy status (Veerkamp and Koenen, 1999). Swali and Wathes (2006) found lower postpartum insulin concentrations in cows originating from sires with a high genetic merit for yield. Even though the number of animals was limited, they estimated that the heritability of postpartum insulin concentration was moderate $\left(\mathrm{h}^{2}=0.43\right)$. In the first 2 mo of lactation, Gutierrez et al. (2006) reported lower insulin concentrations in cows with high genetic merit for yield compared with their low genetic merit counterparts, although their energy balance did not differ. These findings suggest that selection for milk yield implies selection for low insulin concentrations. Similarly, it seems plausible that high-yielding dairy cows may have an inherited predisposition for lower IS, but to our knowledge, data are lacking. In lactating cows, typical manifestations of IR, such as elevated insulin levels and decreased glucose uptake, may be eclipsed by high glucose disposal and low insulin levels during lactation, making it difficult to evaluate IS. Furthermore, breed comparisons of IS may easily be confounded by environmental factors such as diet, condition, gestation, lactation, age, and the medical history of the animal. In neonatal calves, these environmental and metabolic factors can be restricted, and breed differences more closely represent a congenital tendency.

The major aim was to investigate congenital differences in peripheral IS between neonatal Belgian Blue (BB) and Holstein-Friesian (HF) calves. The former breed is reared explicitly for beef production, whereas the latter is exploited specifically for milk production. Peripheral IS was estimated by intravenous glucose tolerance tests (IVGTT), intravenous insulin tolerance tests (IVITT), and 2 estimators of IR established in human medicine (Rabasa-Lhoret et al., 2003): the quantitative insulin sensitivity check index (QUICKI) and the revised QUICKI (RQUICKI). Additionally, a small number of neonatal East Flemish (EF) calves, a local dual-purpose breed, were compared with the 2 other breeds.

\section{MATERIALS AND METHODS}

\section{Selection of the Animals}

All experiments were approved by the Ethical Committee of the Faculty of Veterinary Medicine, Ghent University, Merelbeke, Belgium. For the IVGTT, we selected $10 \mathrm{BB}, 12 \mathrm{HF}$, and $4 \mathrm{EF}$ calves. All calves were healthy and female. Four calves of each breed were subjected to the IVITT $2 \mathrm{~d}$ after the IVGTT. The average age of the calves was $12.9 \pm 0.43 \mathrm{~d}$ for the IVGTT and $14.9 \pm 0.37 \mathrm{~d}$ for the IVITT and did not differ between breeds. Holstein-Friesian calves had a high genetic merit for milk yield (mean genetic index for production: 525.8 $\pm 172.2 \mathrm{~kg}$ above the average of the Flemish Cattle Breeding Association, Oosterzele, Belgium). Calves were weighed on the morning of their experiment; BW were $53.0 \pm 2.0 \mathrm{~kg}$ for the $\mathrm{BB}, 44.1 \pm 2.4 \mathrm{~kg}$ for the $\mathrm{HF}$, and $53.4 \pm 2.1 \mathrm{~kg}$ for the EF calves. The 3 breeds were kept in 3 separate commercial herds but under similar conditions: animals were housed individually in indoor boxes on straw bedding. The ration consisted of bulk milk ( $10 \%$ of the BW/d, evenly divided over 3 meals, at 0800,1400 , and $2000 \mathrm{~h}$ ). All experiments were performed exactly $4 \mathrm{~h}$ after the morning milk feeding; milk refusal before the experiments was negligible. Bulk milk fat contents on the $\mathrm{BB}, \mathrm{HF}$, and $\mathrm{EF}$ farms ranged from 3.88 to $4.42 \%$, from 4.08 to $4.39 \%$, and from 3.92 to $3.95 \%$, respectively, whereas bulk milk protein contents ranged from 3.50 to $3.68 \%, 3.40$ to $3.52 \%$, and 3.19 to $3.44 \%$. Lactose contents were approximately $4.50 \%$, with very little variation among farms (data obtained from the Milk Production Registration by the Flemish Cattle Breeding Association).

\section{IVGTT}

A small surface on a jugular vein was shaved and disinfected. A 12-gauge catheter (Intraflon, Vygon, Brussels, Belgium) was inserted into the jugular vein and fixed to the skin. A $60-\mathrm{cm}$ polyvinyl chloride elongation tube (Dialex-Biomedica, Hasselt, Belgium) was connected to the catheter to avoid manipulation of the calf during blood sampling. Calves were allowed rest for at least 30 min after insertion of the catheter until blood sampling was begun. Stress was avoided as much as possible and the calves generally appeared relaxed during the test. Blood samples were obtained from the catheter in gel-coated or fluorinated blood tubes (Vacutainer, Terumo Europe NV, Leuven, Belgium) at $-15,-5,4,8,12,18,25,36,45$, and 60 min relative to a glucose infusion of $150 \mathrm{mg} / \mathrm{kg}$ of BW (aqueous solution of $300 \mathrm{~g} / \mathrm{L}$; Glucose Dextrose, Eurovet, Heusden- 
Zolder, Belgium), according to the method of Bossaert et al. (2008). Catheters were thoroughly flushed after every infusion or sampling.

\section{IVITT}

The IVITT was performed $2 \mathrm{~d}$ after the IVGTT. Preparation of the calves and time of the experiments were identical to that of the IVGTT. Following the protocol described by Oikawa and Oetzel (2006), blood samples were obtained in gel-coated or fluorinated blood tubes at $-15,-5,15,30$, and 45 min relative to an intravenous infusion of $0.05 \mathrm{IU} / \mathrm{kg}$ of human recombinant insulin (Actrapid, Novo Nordisk Pharma, Brussels, Belgium).

\section{Analyses}

All blood samples were centrifuged $(2,000 \times g, 30$ min) within $1.5 \mathrm{~h}$ after collection, and serum and plasma were stored at $-25^{\circ} \mathrm{C}$ until analysis. All analyses were performed semiautomatically at the Clinical Chemistry Laboratory of the University Hospital (Ghent, Belgium). Interassay coefficients of variation $(\mathbf{C V})$ of all analyses were calculated on a large number of control samples integrated daily in the assays over a long period of time; the intraassay $\mathrm{CV}$ was computed on a regular basis on a smaller number of control samples within 1 assay. Control samples within the physiological and the pathological range were used. Glucose concentrations (mmol/L) were determined by the hexokinase method, followed by colorimetric analysis using the Cobas GLUC2 kit (Roche Diagnostics, Indianapolis, IN). This kit had a detection limit of $0.11 \mathrm{mmol} / \mathrm{L}$ and interand intraassay CV of $<1.15$ and $<0.8 \%$, respectively. Nonesterified fatty acid concentrations $(\mathrm{mmol} / \mathrm{L})$ were measured via an enzymatic method, followed by colorimetric analysis using the NEFA C kit (Wako Chemicals, Richmond, VA). The inter- and intraassay $\mathrm{CV}$ of this kit were $<3$ and $<1.75 \%$, respectively. Insulin $(\mu \mathrm{U} / \mathrm{mL})$ was measured by the electrochemiluminescence immunoassay method using the Cobas Insulin kit (Roche Diagnostics), established in human medicine (Manley et al., 2007). Cross-reactivity between bovine and human insulin was $25 \%$ and was constant within the physiological concentration range. The kit had a detection limit of $0.200 \mu \mathrm{U} / \mathrm{mL}$ and inter- and intraassay $\mathrm{CV}$ of $<4$ and $<2 \%$, respectively.

\section{Calculations}

Basal Concentrations and IVGTT. Basal levels of insulin $\left(\mathbf{I}_{\mathbf{b}}\right)$, glucose $\left(\mathbf{G}_{\mathbf{b}}\right)$, and NEFA $\left(\mathbf{N E F A} \mathbf{A}_{\mathbf{b}}\right)$ were determined as the mean concentration of the 2 blood samples taken before glucose or insulin infusion.
The areas under the curve of insulin $\left(\mathbf{A U C}_{\mathbf{i n s}} ; \mu \mathrm{U} /\right.$ $\mathrm{mL} \times \min )$ and glucose $\left(\mathbf{A} \mathbf{U C}_{\text {gluc }} ; \mathrm{mmol} / \mathrm{L} \times \min \right)$ were computed as the increase in total insulin and glucose above basal levels during the 60 min after infusion. Insulin and glucose peak and nadir concentrations $\left(\mathbf{P}_{\text {ins }}\right.$, $\mathbf{N}_{\text {ins }}$, and $\mathbf{P}_{\text {gluc }}, \mathbf{N}_{\text {gluc }}$, respectively) were determined. Elimination rates of insulin and glucose $\left(\mathbf{E R}_{\text {ins }}, \% /\right.$ min, and $\mathbf{E R}_{\text {gluc }}, \% / \mathrm{min}$, respectively) were computed with the following formulas, as described by Pires et al. (2007):

$$
\begin{gathered}
\mathrm{ER}_{\text {ins }}=\left\{\left(\ln \left[\mathrm{P}_{\text {ins }}\right]-\ln \left[\mathrm{N}_{\text {ins }}\right]\right) /\left(\mathrm{t}_{\mathrm{p}}-\mathrm{t}_{\mathrm{n}}\right)\right\} \times 100, \\
\text { and } \mathrm{ER}_{\text {gluc }}=\left\{\left(\ln \left[\mathrm{P}_{\text {gluc }}\right]-\ln \left[\mathrm{N}_{\text {gluc }}\right]\right) /\left(\mathrm{t}_{\mathrm{p}}-\mathrm{t}_{\mathrm{n}}\right)\right\} \times 100,
\end{gathered}
$$

where $t_{p}$ and $t_{n}$ are the times of the peak and nadir concentrations, respectively.

IVITT. Based on $\mathrm{G}_{\mathrm{b}}$, determined as described above, and the glucose concentrations at $30 \mathrm{~min}\left(\mathbf{G}_{\mathbf{3 0}}\right)$, the insulin-stimulated blood glucose response (ISBGR, \%) was computed. The following formula, as described by Oikawa and Oetzel (2006), was used:

$$
\operatorname{ISBGR}=\left[\left(\mathrm{G}_{\mathrm{b}}-\mathrm{G}_{30}\right) / \mathrm{G}_{\mathrm{b}}\right] \times 100 .
$$

QUICKI and RQUICKI. Basal glucose concentrations were converted from millimoles per liter to milligrams per deciliter. The QUICKI and RQUICKI were calculated as reported by Rabasa-Lhoret et al. (2003):

$$
\begin{gathered}
\text { QUICKI }=1 /\left[\log \left(\mathrm{G}_{\mathrm{b}}\right)+\log \left(\mathrm{I}_{\mathrm{b}}\right)\right], \text { and RQUICKI }= \\
1 /\left[\log \left(\mathrm{G}_{\mathrm{b}}\right)+\log \left(\mathrm{I}_{\mathrm{b}}\right)+\log \left(\mathrm{NEFA}_{\mathrm{b}}\right)\right] .
\end{gathered}
$$

\section{Statistics}

For all statistical analyses, the SPSS software package (version 16.0, SPSS Inc., Chicago, IL) was used. The descriptive statistics are reported as the mean \pm standard error of the mean. All variables were tested for nonnormality using the Kolmogorov-Smirnov method.

All basal metabolite concentrations, IVGTT and IVITT results, and QUICKI and RQUICKI indices were compared in an ANOVA model with breed as a fixed factor (3 categories: BB, HF, and EF). Pair-wise comparisons were made between $\mathrm{BB}, \mathrm{HF}$, and $\mathrm{EF}$ using the least significant difference method. A $P$-value of $<0.05$ was considered statistically significant.

\section{RESULTS}

No signs of nonnormality could be found for basal insulin, glucose, and NEFA concentrations, results of the IVGTT and IVITT, and results of the QUICKI or RQUICKI. 
Table 1. Basal glucose, insulin, and NEFA concentrations, quantitative insulin sensitivity check index (QUICKI), and revised QUICKI (RQUICKI) as estimators of insulin sensitivity in calves of 3 breeds $^{1}$

\begin{tabular}{llllll}
\hline & \multicolumn{3}{c}{ Breed $^{3}$} & & \\
\cline { 2 - 4 } Item $^{2}$ & BB & HF & EF & $\begin{array}{c}\text { Pooled } \\
\text { SEM }\end{array}$ & $\begin{array}{c}\text { Overall } \\
P \text {-value }\end{array}$ \\
\hline $\mathrm{I}_{\mathrm{b}}(\mu \mathrm{U} / \mathrm{mL})$ & $0.35^{\mathrm{a}}$ & $1.58^{\mathrm{b}}$ & $0.94^{\mathrm{ab}}$ & 0.23 & 0.037 \\
$\mathrm{G}_{\mathrm{b}}(\mathrm{mmol} / \mathrm{L})$ & $4.40^{\mathrm{a}}$ & $5.70^{\mathrm{b}}$ & $5.81^{\mathrm{b}}$ & 0.22 & 0.005 \\
NEFA $_{\mathrm{b}}(\mathrm{mmol} / \mathrm{L})$ & 0.24 & 0.25 & 0.15 & 0.020 & 0.27 \\
QUICKI & $0.76^{\mathrm{a}}$ & $0.52^{\mathrm{b}}$ & $0.57^{\mathrm{b}}$ & 0.033 & 0.001 \\
RQUICKI & $1.59^{\mathrm{a}}$ & $0.86^{\mathrm{b}}$ & $1.49^{\mathrm{ab}}$ & 0.12 & 0.010 \\
\hline
\end{tabular}

${ }^{\mathrm{a}, \mathrm{b}}$ Means within a row with different superscripts differ $(P<0.05)$.

${ }^{1}$ All samples were taken before the intravenous glucose tolerance test. ${ }^{2} \mathrm{I}_{\mathrm{b}}=$ basal insulin concentration; $\mathrm{G}_{\mathrm{b}}=$ basal glucose concentration; $\mathrm{NEFA}_{\mathrm{b}}=$ basal NEFA concentration.

${ }^{3}$ Breed: $\mathrm{BB}=$ Belgian-Blue; HF $=$ Holstein-Friesian; $\mathrm{EF}=$ EastFlemish.

\section{Basal Concentrations}

Basal concentrations found before IVGTT are displayed in Table 1 . There was a breed effect on basal insulin and glucose concentrations $(P=0.037$ and $P=$ 0.005 , respectively), whereas basal NEFA levels did not differ between breeds $(P=0.27)$. The $\mathrm{I}_{\mathrm{b}}$ was higher in HF than in BB calves $(P=0.011)$. The $\mathrm{G}_{\mathrm{b}}$ was higher in $\mathrm{HF}$ and $\mathrm{EF}$ compared with $\mathrm{BB}$ calves $(P=0.003$ and $P=0.015$, respectively).

\section{IVGTT and IVITT}

Graphic presentations of the IVGTT and IVITT are provided in Figures 1 and 2, respectively. The resulting outcome variables of the IVGTT and IVITT are presented in Table 2. The $\mathrm{AUC}_{\text {ins }}$ and $\mathrm{P}_{\text {ins }}$ differed between breeds $(P=0.028$ and $P=0.006$, respectively). The $\mathrm{AUC}_{\text {ins }}$ was higher in $\mathrm{HF}$ and $\mathrm{EF}$ calves than in $\mathrm{BB}$ calves $\left(P=0.031\right.$ and $P=0.019$, respectively). The $\mathrm{P}_{\text {ins }}$ was higher in $\mathrm{HF}$ and $\mathrm{EF}$ calves than in $\mathrm{BB}$ calves $(P$ $=0.050$ and $P=0.002$, respectively). The $\mathrm{ER}_{\text {ins }}$ did not differ between breeds $(P=0.401)$. An effect of breed on $\mathrm{AUC}_{\text {gluc }}$ was found $(P=0.012)$. The $\mathrm{AUC}_{\text {gluc }}$ was higher in HF than in BB calves $(P=0.004)$. Glucose elimination rates differed between breeds $(P=0.017)$ : $\mathrm{ER}_{\text {gluc }}$ was lower in $\mathrm{HF}$ calves compared with BB calves $(P=$ $0.005)$. No breed effect on $\mathrm{P}_{\text {gluc }}$ was found $(P=0.27)$.

In accordance with the results of the IVGTT, $\mathrm{G}_{\mathrm{b}}$ found before the IVITT was higher in $\operatorname{HF}(P=0.046)$ and $\mathrm{EF}$ calves $(P=0.003)$ compared with $\mathrm{BB}$ calves. The glucose nadir occurred $30 \mathrm{~min}$ after insulin infusion in all calves. A breed effect on the glucose nadir concentration was found $(P=0.032): \mathrm{G}_{30}$ was higher in $\mathrm{EF}$ than in BB calves $(P=0.011)$. No differences were found in $\mathrm{G}_{30}$ between HF and BB calves $(P=0.122)$ or between $\mathrm{HF}$ and $\mathrm{EF}$ calves $(P=0.166)$. There was no significant breed effect on ISBGR $(P=0.108)$.

\section{QUICKI and RQUICKI}

The results of QUICKI and RQUICKI are presented in Table 1. There was a breed effect for QUICKI and RQUICKI ( $P=0.001$ and $P=0.010$, respectively). The QUICKI was lower in HF and EF calves compared with BB calves $(P<0.001$ and $P=0.024$, respectively). The RQUICKI was lower in HF calves than in BB calves $(P$ $=0.004)$.

\section{DISCUSSION}

The main finding was that after glucose challenge, $\mathrm{HF}$ calves had higher $\mathrm{AUC}_{\text {gluc }}$ and lower $\mathrm{ER}_{\text {gluc }}$ in addition to higher $\mathrm{AUC}_{\text {ins }}$ compared with $\mathrm{BB}$ calves. Together with the higher $I_{b}$ and $G_{b}$ and lower QUICKI and RQUICKI, these results are indicative of breed-specific differences in glucose partitioning and IS. Although calves were located on different farms, their bulk milk originated from different pools and bulk milk protein contents were lower on the EF farm, all calves were housed under similar circumstances, had comparable ages, were fed proportionally to their BW at identical times, and were tested exactly $4 \mathrm{~h}$ after the morning feeding. Glucose concentrations at the beginning of the experiments were comparable with the preprandial glucose levels reported by other authors (Hostettler-Allen et al., 1994; Depew et al., 1998), suggesting that the 4-h waiting period was sufficient to avoid interference of the diet with the metabolic state. Altogether, nutritional differences were expected to be negligible, suggesting that observed differences were breed specific in nature.

Insulin resistance is defined as "a state in which normal insulin concentrations provoke a less than normal biological response" (Kahn, 1978), caused by an increase in the half-effect concentration of insulin, a decrease in the maximal effect of insulin, or their combination. Because insulin has several target sites and a variety of biological responses, the outcome of decreased IS depends on the organ involved. In the liver, insulin inhibits glycolysis, glycogenolysis, and gluconeogenesis. In muscles, insulin stimulates the exteriorization of type 4 glucose transporter molecules (GLUT) and the intracellular processing of glucose. The effect of insulin on adipose tissue is enhanced GLUT 4 and lipoprotein lipase activity and the inhibition of hormone-sensitive lipase. Overall, lower IS results in a decrease in lipogenesis and glucose uptake and an increase in lipolysis and blood glucose levels (Bell and Bauman, 1997; Cunningham and Klein, 2007). In the present study, only the insulin effect on glucose uptake was investigated.

Several methods exist to evaluate IS. The gold standard, the hyperinsulinemic euglycemic clamp, is very time-consuming (Rabasa-Lhoret et al., 2003). A 
A
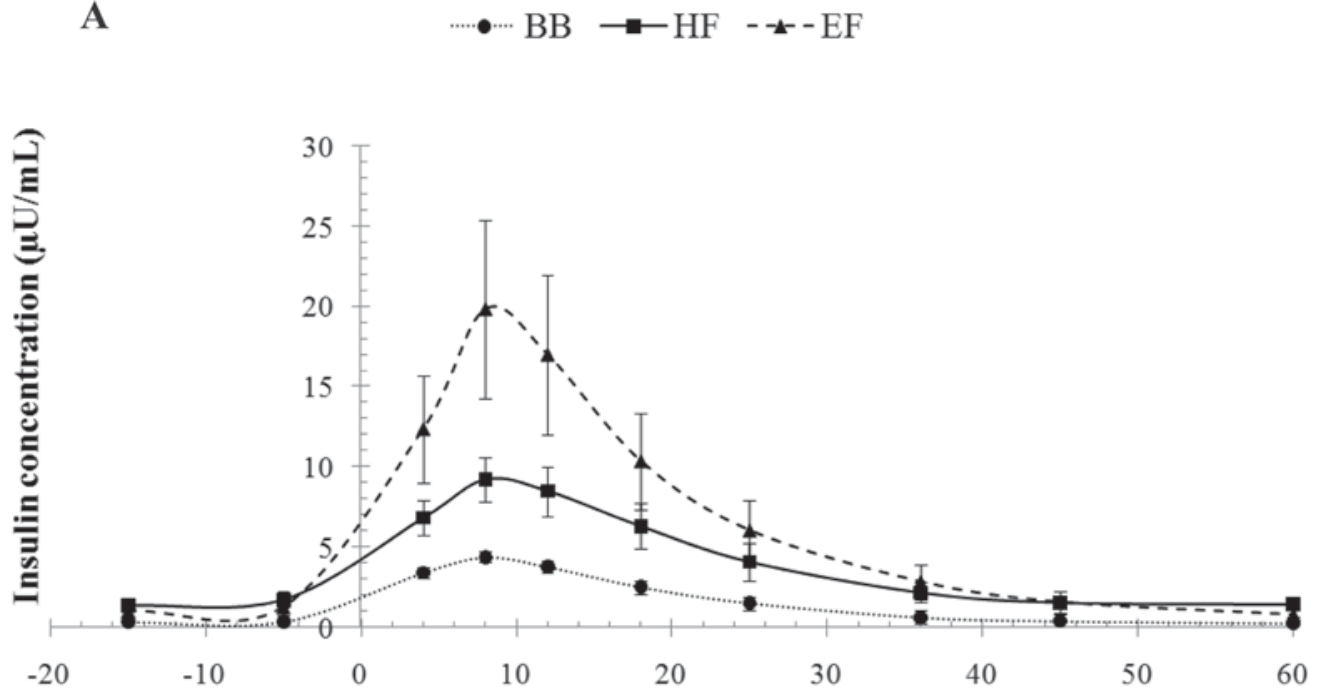

Time relative to glucose infusion $(\mathrm{min})$

B

$\cdots \cdot \cdots \mathrm{BB} \rightarrow-\mathrm{HF}-\longleftarrow-\mathrm{EF}$

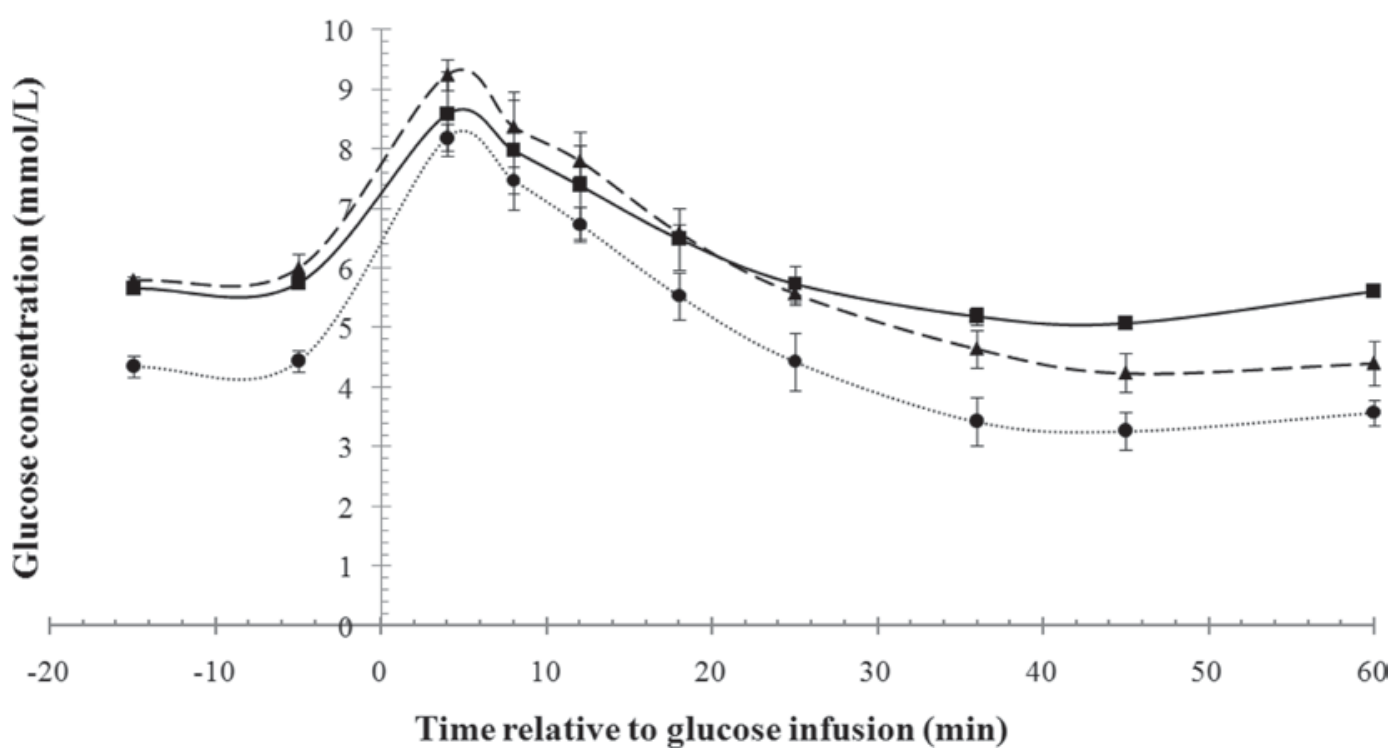

Figure 1. Insulin (A) and glucose (B) responses at different time points relative to an intravenous infusion $(=$ time 0$)$ of $150 \mathrm{mg} / \mathrm{kg}$ of glucose in calves of 3 breeds. Markers represent the average concentration; error bars represent the SEM. BB = Belgian Blue; HF = Holstein-Friesian; $\mathrm{EF}=$ East Flemish

more practical approach is the IVGTT, which has a disadvantage in lactating animals. Intracellular glucose uptake occurs via GLUT molecules. Striated muscles and adipose tissue contain insulin-independent GLUT 1 for the basal glucose supply and insulin-dependent GLUT 4, whereas the mammary gland contains mainly insulin-independent GLUT 1 and 3 (Duehlmeier et al., 2005; Zhao et al., 2006). During lactation, glucose clearance may be an inadequate measure of IS because up to $80 \%$ of all available glucose is consumed independently of insulin by the mammary gland (Bauman and Currie,
1980). In calves, the mammary gland is inactive and striated muscle is the main site of glucose uptake, and hence of differences in IS (Duehlmeier et al., 2007), and the increase in glucose uptake under elevated insulin concentrations is mainly insulin dependent (Duehlmeier et al., 2005). Another method is the IVITT, in which ISBGR is a measure for IS (Oikawa and Oetzel, 2006). Finally, QUICKI and RQUICKI are established methods in human medicine; these indices, based on fasting metabolite concentrations, corresponded closely to the results obtained by the hyperinsulinemic euglycemic 
Table 2. Outcome variables from the intravenous glucose tolerance test (IVGTT) and the intravenous insulin tolerance test (IVITT) in calves of 3 breeds

\begin{tabular}{lccccc}
\hline & \multicolumn{3}{c}{ Breed $^{2}$} \\
\cline { 2 - 3 } Item $^{1}$ & $\mathrm{BB}$ & $\mathrm{HF}$ & $\mathrm{EF}$ & Pooled SEM & Overall $P$-value \\
\hline Response to glucose challenge & & & & & \\
$\mathrm{AUC}_{\text {ins }}(\mu \mathrm{U} / \mathrm{mL} \cdot \mathrm{min})$ & $86.71^{\mathrm{a}}$ & $222.65^{\mathrm{b}}$ & $293.69^{\mathrm{b}}$ & 30.45 & 0.028 \\
$\mathrm{P}_{\text {ins }}(\mu \mathrm{U} / \mathrm{mL})$ & $4.62^{\mathrm{a}}$ & $9.70^{\mathrm{b}}$ & $16.44^{\mathrm{b}}$ & 1.34 & 0.006 \\
$\mathrm{ER}_{\text {ins }}(\% / \mathrm{min})$ & 4.84 & 3.81 & 4.16 & 0.34 & 0.401 \\
$\mathrm{AUC}_{\text {gluc }}(\mathrm{mmol} / \mathrm{L} \cdot \mathrm{min})$ & $256.22^{\mathrm{a}}$ & $335.66^{\mathrm{b}}$ & $321.03^{\mathrm{ab}}$ & 13.04 & 0.012 \\
$\mathrm{P}_{\text {gluc }}(\mathrm{mmol} / \mathrm{L})$ & 8.20 & 8.58 & 9.07 & 0.18 & 0.266 \\
$\mathrm{ER}_{\text {gluc }}(\% / \mathrm{min})$ & $2.35^{\mathrm{b}}$ & $1.37^{\mathrm{a}}$ & $1.87^{\mathrm{ab}}$ & 0.16 & 0.017 \\
Response to insulin challenge $_{\mathrm{G}_{\mathrm{b}}(\mathrm{mmol} / \mathrm{L})}$ & $4.53^{\mathrm{a}}$ & $5.18^{\mathrm{b}}$ & $5.63^{\mathrm{b}}$ & 0.17 & 0.011 \\
$\mathrm{G}_{30}(\mathrm{mmol} / \mathrm{L})$ & $1.18^{\mathrm{a}}$ & $1.78^{\mathrm{ab}}$ & $2.30^{\mathrm{b}}$ & 0.19 & 0.032 \\
ISBGR $(\%)$ & 0.75 & 0.64 & 0.59 & 0.030 & 0.108 \\
\hline
\end{tabular}

${ }^{\mathrm{a}, \mathrm{b}}$ Means within a row with different superscripts differ $(P<0.05)$.

${ }^{1} \mathrm{AUC}_{\text {ins }}=$ insulin area under the curve; $\mathrm{P}_{\text {ins }}=$ insulin peak concentration; $\mathrm{ER}_{\text {ins }}=$ insulin elimination rate; $\mathrm{AUC}_{\text {gluc }}=$ glucose area under the curve; $\mathrm{P}_{\text {gluc }}=$ glucose peak concentration; $\mathrm{ER}_{\text {gluc }}=$ glucose elimination rate; $\mathrm{G}_{\mathrm{b}}=$ basal glucose concentration; $\mathrm{G}_{30}=$ glucose concentration 30 min after insulin infusion; ISBGR = insulinstimulated blood glucose response.

${ }^{2}$ Breed: $\mathrm{BB}=$ Belgian Blue; HF = Holstein-Friesian; EF = East Flemish.

clamp method (Rabasa-Lhoret et al., 2003). A lower RQUICKI, as found in obese and diabetic individuals, was indicative of decreased IS. Recently, a lower result was found in obese cows compared with their thinner counterparts (Holtenius and Holtenius, 2007).

Basal glucose concentrations were higher in $\mathrm{HF}$ and $\mathrm{EF}$ than in $\mathrm{BB}$ calves. Basal insulin concentrations were higher in HF compared with $\mathrm{BB}$ calves. The HF and
EF calves had a higher $\mathrm{AUC}_{\text {ins }}$ and $\mathrm{P}_{\text {ins }}$ after glucose infusion, whereas $\mathrm{ER}_{\text {ins }}$ did not differ, suggesting greater glucose-induced insulin secretion. The high basal and evoked insulin concentrations in $\mathrm{HF}$ and $\mathrm{EF}$ calves were unexpected because others suggest a genetic tendency toward low insulin levels in breeds selected for milk yield (Veerkamp et al., 2003; Gutierrez et al., 2006). This finding indicated that metabolic and physiological

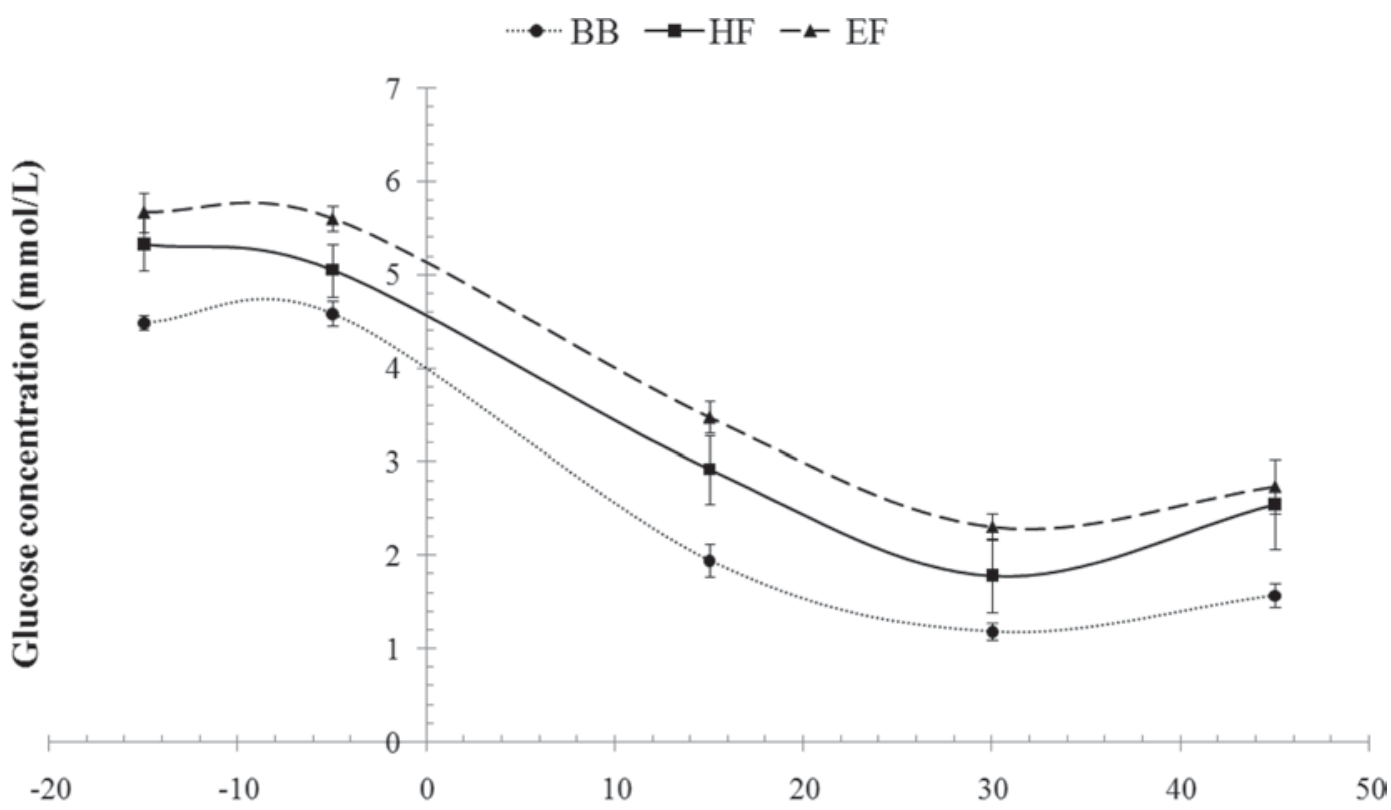

Time relative to insulin infusion (min)

Figure 2. Glucose response at different time points relative to an intravenous infusion (= time 0$)$ of $0.05 \mathrm{IU} / \mathrm{kg}$ of insulin in calves of 3 breeds. Markers represent the average glucose concentration; error bars represent the SEM. $\mathrm{BB}=$ Belgian Blue; HF $=\mathrm{Holstein}-\mathrm{Friesian}$; EF $=$ East Flemish. 
differences between neonatal, pseudomonogastric calves and adult, polygastric, lactating cows may be considerable. High pancreatic insulin secretion in HF calves may result from low glucose clearance rates and IS. Hammon et al. (2007) found markedly lower glucoseinduced insulin responses in crossbred heifers with a higher milk yield compared with their lower yielding counterparts, but importantly, this difference was apparent only during lactation. Altogether, we propose that the tendency toward low insulin secretion in HF may be concealed at a younger age and may emerge under circumstances of increased metabolic pressure, such as late pregnancy and lactation. It is important to stress that caution is in order when extrapolating data from young animals to adults.

After glucose infusion, $\mathrm{HF}$ calves had higher $\mathrm{AUC}_{\text {gluc }}$ than BB calves. Glucose concentrations during IVGTT depend on glucose consumption by peripheral tissues, endogenous glucose production, renal glucose excretion, and intestinal glucose absorption (Pires et al., 2007). Residual hepatic glucose production during IVGTT cannot be excluded (Hostettler-Allen et al., 1994). Although glucose production was not measured, in the case of a difference, BB calves would hypothetically have a higher rate of gluconeogenesis because of their lower insulin levels, and it is implausible that the lower $\mathrm{AUC}_{\text {gluc }}$ in $\mathrm{BB}$ calves is caused by differences in gluconeogenesis. In addition, small differences in the glucose filtration rate during IVGTT are possible because the renal glucose threshold of $8.3 \mathrm{mmol} / \mathrm{L}$ (Hostettler-Allen et al., 1994) was exceeded in most calves. Hypothetically, should there have been a difference, then HF and EF calves would have had higher urinary glucose losses because of their slightly higher $\mathrm{P}_{\text {gluc }}$ compared with $\mathrm{BB}$ calves, and it is implausible that the higher $\mathrm{AUC}_{\text {gluc }}$ in $\mathrm{HF}$ and $\mathrm{EF}$ calves was caused by differences in renal filtration rate. Finally, no differences in intestinal glucose absorption were expected because all calves received similar rations and were tested $4 \mathrm{~h}$ after the morning feeding. We propose that the difference in $\mathrm{AUC}_{\text {gluc }}$ was caused by a breed difference in peripheral glucose uptake, as suggested by the results for $\mathrm{ER}_{\text {gluc }}$.

The BB breed was systematically selected for double muscling. The muscle proportion in double-muscled individuals is roughly $20 \%$ higher than in normally muscled cattle (Shahin and Berg, 1985), which may contribute to the higher $\mathrm{ER}_{\text {gluc }}$ in $\mathrm{BB}$ calves. However, higher basal and glucose-induced insulin concentrations, higher $\mathrm{G}_{\mathrm{b}}$, and lower QUICKI and RQUICKI in HF calves suggest that, apart from differences in muscle mass, breed differences in IS play a part in the $\mathrm{ER}_{\text {gluc }}$ differences. The low $\mathrm{ER}_{\text {gluc }}$ in $\mathrm{HF}$ calves may be in line with their potential for glucose partitioning toward the mammary gland at the onset of lactation, whereas the higher IS observed in BB calves may reflect their extensive potential for tissue accretion. In neonatal pigs, an increased activation of insulin-signaling components was associated with a high degree of muscle protein synthesis (Suryawan et al., 2007). Although no sound conclusions can be drawn about the EF group because of their small number, their $\mathrm{ER}_{\text {gluc }}$, QUICKI, and RQUICKI were situated between those of $\mathrm{HF}$ and $\mathrm{BB}$ calves, which may be consistent with the dual-purpose exploitation of this breed. After an insulin challenge, $\mathrm{HF}$ and EF calves maintained glucose on a higher level compared with BB calves, but no significant breed differences in ISBGR were found, possibly because of the small number of calves in the IVITT compared with the IVGTT and RQUICKI.

Apart from the transient IR state observed in virtually all mammal species during pregnancy, lactation, starvation, and obesity, an innate background for IR is recognized. In humans, for instance, young, healthy, and lean offspring of diabetes mellitus type II patients have a higher risk for metabolic disorders later in life. Their glucose tolerance is generally impaired long before the onset of clinical signs. Although the genes involved in the heritability of IR are not known, impaired GLUT 4 transcription and glucose uptake in skeletal muscles is a genetically determined defect, as reviewed by Petersen and Shulman (2006). Because negative energy balance is often present in dairy cows for several weeks after calving and during early gestation (Bauman and Currie, 1980), differences in the oviductal or uterine environment during the embryonic or fetal stages may have contributed to the observed breed differences in IS. It is not possible, based on the current data, to distinguish between genetic or epigenetic causes.

In conclusion, the results from the IVGTT demonstrate breed-specific differences in glucose partitioning. Particularly striking was the lower glucose elimination rate in combination with higher insulin responses in $\mathrm{HF}$ calves compared with BB calves, suggesting lower IS in HF calves compared with BB calves. The QUICKI and RQUICKI results supported the results from the IVGTT. Because nutritional differences between calves were minimal, differences in IS are proposed to be congenital in nature. We hypothesize that selection for tissue accretion implies selection for higher IS, whereas selection for milk yield may result in lower IS, supporting energy partitioning toward the mammary gland but increasing the risk for metabolic and reproductive disorders. Because of substantial differences between newborn and adult animals, these data should be interpreted toward the lactating stage with caution. 


\section{ACKNOWLEDGMENTS}

This research was funded by the Special Research Fund, Ghent University, grant number 01D29105.

\section{REFERENCES}

Bauman, D. E., and W. B. Currie. 1980. Partitioning of nutrients during pregnancy and lactation: A review of mechanisms involving homeostasis and homeorhesis. J. Dairy Sci. 63:1514-1529.

Bell, A. W. 1995. Regulation of organic nutrient metabolism during transition from late pregnancy to early lactation. J. Anim. Sci. 73:2804-2819.

Bell, A. W., and D. E. Bauman. 1997. Adaptations of glucose metabolism during pregnancy and lactation. J. Mammary Gland Biol. Neoplasia 2:265-278.

Bossaert, P., J. L. M. R. Leroy, S. De Vliegher, and G. Opsomer. 2008. Interrelations between glucose-induced insulin response, metabolic indicators and time of first ovulation in high yielding dairy cows. J. Dairy Sci. 91:3363-3371.

Cunningham, J. G., and B. G. Klein. 2007. Endocrine glands and their function. Pages 428-464 in Textbook of Veterinary Physiology. 4th ed. Saunders/Elsevier, St. Louis, MO.

Depew, C. L., L. D. Bunting, J. M. Fernandez, D. L. Thompson, and R. W. Adkinson. 1998. Performance and metabolic responses of young dairy calves fed diets supplemented with chromium tripicolinate. J. Dairy Sci. 81:2916-2923.

Duehlmeier, R., A. Hacker, A. Widdel, W. von Engelhardt, and H. Sallmann. 2005. Mechanisms of insulin-dependent glucose transport into porcine and bovine skeletal muscle. Am. J. Physiol. Regul. Integr. Comp. Physiol. 289:187-197.

Duehlmeier, R., K. Sammet, A. Widdel, W. von Engelhardt, U. Wernery, J. Kinne, and H. P. Sallmann. 2007. Distribution patterns of the glucose transporters GLUT4 and GLUT1 in skeletal muscles of rats (Rattus norvegicus), pigs (Sus scrofa), cows (Bos taurus), adult goats, goat kids (Capra hircus), and camels (Camelus dromedarius). Comp. Biochem. Physiol. 146:274-282.

Gutierrez, C. G., J. G. Gong, T. A. Bramley, and R. Webb. 2006. Selection on predicted breeding value for milk production delays ovulation independently of changes in follicular development, milk production and body weight. Anim. Reprod. Sci. 95:193-205.

Hammon, H. M., O. Bellmann, J. Voigt, F. Schneider, and C. Kühn. 2007. Glucose-dependent insulin response and milk production in heifers within a segregating resource family population. J. Dairy Sci. 90:3247-3254.

Holtenius, P., and K. Holtenius. 2007. A model to estimate insulin sensitivity in dairy cows. Acta Vet. Scand. 49:29-31.

Hostettler-Allen, R. L., L. Tappy, and J. W. Blum. 1994. Insulin resistance, hyperglycemia, and glucosuria in intensively milk-fed calves. J. Anim. Sci. 72:160-173.

Kahn, C. R. 1978. Insulin resistance, insulin sensitivity, and insulin unresponsiveness: A necessary distinction. Metabolism 27:18931902.

Leroy, J. L. M. R., T. Vanholder, A. T. M. Van Knegsel, I. GarciaIspierto, and P. E. J. Bols. 2008. Nutrient prioritization in dairy cows early postpartum: Mismatch between metabolism and fertility? Reprod. Domest. Anim. 43:96-103.

Lucy, M. C. 2001. Reproductive loss in high-producing dairy cattle: Where will it end? J. Dairy Sci. 84:1277-1293.

Manley, S. E., I. M. Stratton, P. M. Clark, and S. D. Luzio. 2007. Comparison of 11 human insulin assays: Implications for clinical investigation and research. Clin. Chem. 5:922-932.

Oikawa, S., and G. R. Oetzel. 2006. Decreased insulin response in dairy cows following a four-day fast to induce heaptic lipidosis. J. Dairy Sci. 89:2999-3005.

Petersen, K. F., and G. I. Shulman. 2006. Etiology of insulin resistance. Am. J. Med. 119:S10-S16.

Pires, J. A., A. H. Souza, and R. R. Grummer. 2007. Induction of hyperlipidemia by intravenous infusion of tallow emulsion causes insulin resistance in Holstein cows. J. Dairy Sci. 90:2735-2744.

Rabasa-Lhoret, R., J. P. Bastard, V. Jan, P. H. Ducluzeau, F. Andreelli, F. Guebre, J. Bruzeau, C. Louche-Pellissier, C. Maîtrepierre, J. Peyrat, J. Chagné, H. Vidal, and M. Laville. 2003. Modified quantitative insulin sensitivity check index is better correlated to hyperinsulinemic glucose clamp than other fasting-based index of insulin sensitivity in different insulin-resistant states. J. Clin. Endocrinol. Metab. 88:4917-4923.

Shahin, K. A., and R. T. Berg. 1985. Growth patterns of muscle, fat, and bone, and carcass composition of double muscled and normal cattle. Can. J. Anim. Sci. 65:279-293.

Suryawan, A., R. A. Orellana, H. V. Nguyen, A. S. Jeyapalan, J. R. Fleming, and T. A. Davis. 2007. Activation by insulin and amino acids of signaling components leading to translation in skeletal muscle of neonatal pigs is developmentally regulated. Am. J. Physiol. Endocrinol. Metab. 293:1597-1605.

Swali, A., and D. C. Wathes. 2006. Influence of the dam and sire on size at birth and subsequent growth, milk production and fertility in dairy heifers. Theriogenology 66:1173-1184.

van Knegsel, A. T. M., H. van den Brand, E. A. M. Graat, J. Dijkstra, R. Jorritsma, E. Decuypere, S. Tamminga, and B. Kemp. 2007. Dietary energy source in dairy cows in early lactation: Metabolites and metabolic hormones. J. Dairy Sci. 90:1477-1485.

Veenhuizen, J. J., J. K. Drackley, M. J. Richard, T. P. Sanderson, L. D. Miller, and J. W. Young. 1991. Metabolic changes in blood and liver during development and early treatment of experimental fatty liver and ketosis in cows. J. Dairy Sci. 74:4238-4253.

Veerkamp, R. F., B. Beerda, and T. van der Lende. 2003. Effects of genetic selection for milk yield on energy balance, levels of hormones, and metabolites in lactating cattle, and possible links to reduced fertility. Livest. Prod. Sci. 83:257-275.

Veerkamp, R. F., and E. P. C. Koenen. 1999. Genetics of food intake, live weight, condition score and energy balance. Pages 63-73 in Occ. Pub. Br. Soc. Anim. Sci. no. 24. Br. Soc. Anim. Sci., Edinburgh, UK.

Zhao, F. Q., W. M. Moseley, H. A. Tucker, and J. J. Kennelly. 2006. Regulation of glucose transporter gene expression in mammary gland, muscle, and fat of lactating cows by administration of bovine growth hormone and bovine growth hormone-releasing factor. J. Anim. Sci. 74:183-189. 